\title{
Construindo a aprendizagem a partir do mundo da arte, brincadeira e música
}

\section{Creación de aprendizaje del mundo del arte, el juego y la música}

\author{
Building learning from the world of art, play and music
}

Sandra da Silva Martins ${ }^{1}$

\begin{abstract}
Resumo
Este trabalho consiste no relato de um projeto educacional realizado com alunos do Pré II, em uma escola da rede Municipal da cidade de Jaguarão Rs. As práticas docentes foram desenvolvidas com os objetivos de analisar as contribuições dos planos de aulas organizados, a partir do princípio do fio condutor "Construindo a Aprendizagem a Partir do Mundo da Arte, Brincadeira e Música", a fim de provocar os alunos à reflexão para que reconstruíssem suas aprendizagens. Abordar-se-á, Metodologias e atividades desenvolvidas com a turma durante o projeto. Ao final de cada plano de aula é apresentado as reflexões acerca da prática docente e construção de aprendizagens pelos alunos. Para fundamentar utilizou-se o Referencial Curricular para a educação infantil (1998), Hernandez (1998), Tardif (2007). Este trabalho contribuiu para que todos os alunos se envolvessem com as atividades propostas, pois os conteúdos trabalhados apresentavam sentido para a vida dos mesmos. Com este percebeu-se a importância de organizar, planejar aulas que vão ao encontro do que o aluno já sabe, fazendo com que construam novos conhecimentos. Sendo assim, espera-se que por meio destas experiências no ambiente escolar, possa-se contribuir com reflexões para ampliar as questões que envolvem aulas planejadas a partir do tema Arte, Música e brincadeiras.
\end{abstract}

Palavras-Chave: Aprendizagem. Planejamento. Prática docente.

\section{Resumen}

Este articulo es el informe de un proyecto educativo llevado a cabo con estudiantes de Pre II, en una escuela de la red municipal de la ciudad de Jaguarão Rs. Se desarrollaron prácticas de enseñanza con el fin de analizar las contribuciones de los planes de lecciones organizadas, basados en el principio rector "Construyendo el aprendizaje del mundo del arte, el juego y la música", para provocar que los estudiantes reflexionen sobre para reconstruir su aprendizaje. Cubrirá metodologías y actividades desarrolladas con la clase durante el proyecto. $\mathrm{Al}$ final de cada plan de lección se presentan las reflexiones sobre la práctica docente y la construcción del aprendizaje por parte de los estudiantes. Para apoyar esto, utilizamos el Marco Curricular para la educación de la primera infancia (1998), Hernández (1998), Tardif (2007). Este trabajo contribuyó a que todos los estudiantes se involucraran con las actividades propuestas, porque los contenidos trabajados presentaban un significado para sus vidas. Con esto, se dio cuenta de la importancia de organizar, planificar clases que cumplan con lo que el

${ }^{1}$ Graduada em Pedagogia e Pós Graduada em Psicopedagogia pela Universidade Federal do Pampa (UNIPAMPA). Especializada em Alfabetização e Letramento, pela Faculdade de Educação São Luís de Jaboticabal/SP. Mestranda em educação pelo PPGEdu da Universidade Federal do Pampa (UNIPAMPA). sandra_magrif@hotmail.com 
estudiante ya sabe, lo que hace que desarrollen nuevos conocimientos. Por lo tanto, se espera que a través de estas experiencias en el entorno escolar, podamos contribuir con reflexiones para ampliar los temas relacionados con las lecciones planificadas del tema Arte, Música y juegos.

Palabras claves: Aprendizaje. Planificación. Práctica docente.

\begin{abstract}
This article is the report of an educational project carried out with students from Pre II, in a school of the municipal network of the city of Jaguarão Rs. Teaching practices were developed in order to analyze the contributions of the organized lesson plans, based on the guiding principle "Building Learning from the World of Art, Play and Music", in order to provoke students to reflect on to rebuild their learning. It will cover methodologies and activities developed with the class during the project. At the end of each lesson plan are presented the reflections on teaching practice and learning construction by students. To support this, we used the Curriculum Framework for early childhood education (1998), Hernandez (1998), Tardif (2007). This work contributed for all students to get involved with the proposed activities, because the contents worked presented meaning to their lives. With this it was realized the importance of organizing, planning classes that meet what the student already knows, making them build new knowledge. Thus, it is hoped that through these experiences in the school environment, we can contribute with reflections to broaden the issues involving lessons planned from the theme Art, Music and games.
\end{abstract}

Keywords: Learning. Planning. Teaching practice.

\title{
1. Introdução
}

Este trabalho consiste no relato de um projeto educacional elaborado na Educação Infantil, por professoras com formação em pedagogia pela Universidade Federal do Pampa (UNIPAMPA) realizado entre os meses de março e abril de 2018, com alunos do Pré II, em uma escola da rede Municipal da cidade de Jaguarão Rs.

Este projeto, tem como objetivo principal, analisar as contribuições dos planos de aulas organizados, a partir do princípio do fio condutor "Construindo a Aprendizagem a Partir do Mundo da Arte, Brincadeira e Música" a fim de provocar os alunos à reflexão para que reconstruíssem suas aprendizagens através de atividades que envolvessem os princípios do fio condutor acima citado, procurando assim trabalhar o desenvolvimento corporal, provocar a interação, pois segundo o que foi proporcionado nas disciplinas teóricas no curso de pedagogia, se torna necessário que a criança tenha o seu momento de brincar exercitar o corpo. Conforme o Referencial Curricular para a educação infantil Conhecimento de mundo. Brasília, MEC//SEF, 1998. V.3, P.30. 


\begin{abstract}
"Brincadeiras que envolvam o canto e o movimento, simultaneamente, possibilitam a percepção rítmica a identificação de segmentos do corpo e o contato físico. A cultura popular infantil é uma riquíssima fonte na qual se pode buscar cantigas e brincadeiras de cunho afetivo nas quais o contato corporal é o seu principal conteúdo"
\end{abstract}

As atividades com música e brincadeiras proporcionam a interação entre as crianças, à socialização, as trocas de aprendizagem e o desenvolvimento da cognição. A música a brincadeira em si, desperta a capacidade criadora da criança, estas auxiliam no desenvolvimento de suas potencialidades estimulando e ampliando a linguagem oral do grupo e o vocabulário, promovendo situações em que a criança desenvolva sua capacidade de ouvir, expressar e ampliar o seu repertório de palavras.

Utilizou-se como "os eixos possíveis e seus desdobramentos" no plano de ensino os seguintes temas: Criança gosta de brincar, Brincadeira de criança como é bom, No ritmo da brincadeira, Quem brinca encanta seu mal espanta, procurando contemplar os seguintes objetivos: Reconhecer e descrever características de determinada obra de arte; Analisar e fazer releitura de imagens e música; Apreciar leitura de livros; Resgatar as brincadeiras as cantigas de roda, buscando despertar o interesse dos alunos por diferentes estilos de brincadeiras.

A avaliação foi de forma observatória, se as crianças participavam com interesse das atividades desenvolvidas, eram observados os conhecimentos que os alunos adquiriram através do relato da posição destes frente às novas descobertas.

\begin{abstract}
A avaliação com um sentido significativo não é só a avaliação dos alunos. É, sobretudo, a contrastação das intenções da professora com sua prática. O resultado é sempre o início do planejamento de intervenção posterior. Na organização da classe mediante Projetos de trabalho esta interconexão se torna evidente. (HERNANDEZ, 1998, p.91).
\end{abstract}

Primeiramente abordar-se-á sobre as metodologias adotadas para o desenvolvimento das atividades, para isso, descreve-se alguns planos de aula desenvolvidos com a turma durante as aulas, sendo que cada plano aborda uma música a qual pode ser trabalhado diversos conteúdos, relacionando o tema da cantiga com uma determinada situação problema, em cada plano de aula será apresentado reflexões acerca da prática docente e construção de aprendizagens pelos alunos.

Acredita-se que os planos de aulas que são organizados a partir do conhecimento prévio que o aluno possui, venham a possibilitar com que o aluno faça a construção de novas aprendizagens a partir de interações e experiências vivenciadas, tornando-se a aprendizagem mais significativa para estes, pois os educandos têm a oportunidade de trocarem informações, 
construir hipóteses sobre um determinado assunto. Sendo assim, os planos de aula foram organizados a partir desta perspectiva e isto poderá ser comprovado a seguir, no corpo deste trabalho.

É válido dizer que antes da aplicação do projeto educacional, preparou-se uma semana de observação, pois percebe-se, que a partir da observação já é possível perceber os problemas que vão surgindo com a turma, a desenvolver a prática pedagógica, e foi exatamente neste momento que se alcançou o entendimento de qual seria a escolha do tema do fio condutor do projeto: "Construindo a Aprendizagem a Partir do mundo da arte, brincadeira e música".

Verificou-se a necessidade de os educandos reconstruírem suas aprendizagens a partir da brincadeira, do canto e do movimento corporal e principalmente por serem esses alunos de uma faixa etária que ainda requer muito "o brincar" para o seu desenvolvimento em geral. E para começar a pratica buscou-se na cultura popular infantil, brincadeiras e cantigas, para propor atividades que proporcionassem tais aprendizagens aos alunos.

No início da pratica pedagógica houve uma preocupação quanto ao alcanço do envolvimento entre os alunos com as atividades escolhidas, se realmente estes conseguiriam construir suas aprendizagens a partir do tema que se havia proposto. Não se poderia vacilar na escolha, pois acredita-se que o professor tem que se desafiar, buscar, procurar novos meios para que o grupo de alunos venham a refletir sobre as atividades que o professor propõe.

\footnotetext{
Uma das atividades do docente após a escolha do tema é "criar um clima de envolvimento no grupo, e em cada pessoa, sobre o que se está trabalhando na sala de aula. Ou seja, reforçar a consciência de aprender do grupo". (HERNÁNDEZ,1998, p.69).
}

Com a possibilidade do envolvimento do grupo inicia-se a primeira semana em sala de aula. Foi proposto na primeira aula, como atividade, que os alunos tivessem acesso a diversas imagens de brincadeiras por exemplo: bola, boneca, carrinho, pula corda, brincadeira de roda, foram distribuídas imagens e os alunos incentivados para que escolhessem as quais mais se identificassem com as das brincadeiras que mais gostavam. Nessa mediação perguntando a cada um individualmente, para que relatassem como se brinca com tal brincadeira a qual escolheu e assim as professoras possibilitaram que os alunos fizessem a escolha que a turma mais gosta, em seguida estes confeccionaram um cartaz com as referidas brincadeiras. $\mathrm{O}$ objetivo da aula era propiciar a interação entre a turma e ter certeza de que o tema do projeto de trabalhar a música seria realmente algo que chamaria a atenção dos educandos e assim para surpresa, estes escolheram entre tantas imagens, as brincadeiras de roda de cantigas, e 
passaram a interagir o tempo todo uns com os outros, desta forma, percebendo ao fazer o cartaz que se escreve com letras, pois neste foi escrito em letra palito o título "BRINCADEIRA QUE MAIS GOSTAMOS".

Em outra aula foi proporcionado aos alunos à contação de história do livro: “Quer brincar de Pique Esconde” do Projeto Trilhas. Em um primeiro momento os alunos foram convidados para irem ao pátio da escola, lá se sentaram em círculo. E a professora se apropriando exclusivamente da contribuição dos seus gestos corporais, de sua voz e expressões faciais começou a contar a história, estimulados pelo texto contado os alunos participavam encantados apreciando a cada momento da história. Logo depois foi solicitado que estes fizessem a releitura através da pintura do que entenderam da história e todos participaram seduzidos pela história, o que foi muito enriquecedor, pois acredita-se que a leitura se constrói também através das deduções, dos atos de fala, que o aluno aprende através da interação entre todos, aluno com aluno, aluno e professor.

E assim foi se passando a primeira semana, os alunos começaram a se motivar com as atividades propostas, entre estas atividades uma foi em especial para nós, foi apresentado para as crianças as obras do artista plástico brasileiro, Candido Portinari, em que o pintor retratou as brincadeiras de sua infância entre estas obras de arte a "Roda Infantil" que mostra a brincadeira de roda. Logo em seguida foi mostrado para estes a releitura que o também pintor e desenhista Milton Rodrigues da Costa fez da obra de arte "roda infantil" uma releitura muito colorida que parece mexer, com a imaginação da criança, E que de acordo com os Parâmetros Curriculares Nacionais- Arte $\left(1^{\circ} \mathrm{e} 2^{\circ}\right.$ ciclos do Ensino Fundamental) "A educação em arte propicia o desenvolvimento do pensamento artístico, que caracteriza um modo particular de dar sentido as experiências das pessoas: por meio dele, o aluno amplia a sensibilidade, a percepção, a reflexão e a imaginação.

E assim os alunos apreciavam as obras de arte e recebiam a explicação do ano em que havia sido pintado, o material que os pintores haviam usado, era notório pela educadora o interesse dos alunos e o encanto destes pelas obras de arte e pela música. Logo em seguida foi sugerido que cada aluno agora fizesse a sua releitura a partir do que haviam visto na cena retratada nas obras de arte de Candido Portinari e Milton da Costa, foram distribuídas folhas de papel oficio e tintas, e estes começaram a pintar, usando a sua imaginação. Quando a professora percebeu que alguns dos alunos começaram a cantar e falar sobre as brincadeiras que conheciam sem que esta tivesse feito algum tipo de intervenção, um aluno chegou a comentar que a sua releitura era mais bonita que a obra de arte de Candido Portinari. 
Com esta aula percebeu-se termos alcançado o ideal, de começar a resgatar as brincadeiras de roda a música e as cantigas, as crianças começaram a ampliar o desenvolvimento do contato social com os outros colegas, passaram a ampliar o repertório e a estes educadores conseguimos trazer o conhecimento, partindo do mundo da arte.

Nas palavras de Barbosa (1999, p.99).

\begin{abstract}
"Não basta dizer que a arte deve ser estudada como assunto específico no currículo escolar sem mencionar mais especificamente o que significa buscar a excelência desse ensino. A meta geral do ensino da arte é o desenvolvimento da disposição de apreciar obras de arte, onde excelência da arte implica dois fatores: a extrema capacidade que temos trabalhos de arte de intensificar e ampliar o âmbito do conhecimento e experiência humanos e as qualidades peculiares de trabalhos artísticos dos quais resulta tal capacidade. Ou, de forma mais resumida, a meta desse ensino é desenvolver nos jovens a disposição de apreciar a excelência nas artes em função da experiência maior que a arte é capaz de proporciona".
\end{abstract}

Na segunda semana procurou-se desenvolver atividades com que os alunos passassem a perceber através das letras das músicas expostas em cartazes na sala de aula, que se escreve com letras e que conforme escutassem as cantigas, estes conseguissem explorar o ritmo das melodias integrado a movimentos com as mãos, ou seja, que estes executassem movimentos, que exigissem atenção e memória (coreografia) no caso a música "pirulito que bate, bate", que também proporcionou ser trabalhado a coordenação motora e a criatividade dos alunos. Pois acredita-se que se deva estimular os alunos a praticarem exercícios que envolvam o corpo, para que estes tenham a possibilidade de buscar a autonomia dos movimentos corporais.

Outra atividade realizada e que se torna de fundamental importância, foi trabalhar a música "pezinho" com o intuito de que os alunos reconhecessem a música tradicional gaúcha, para que percebessem ao ouvirem através do ritmo e do lúdico que se compõe, que esta faz parte da tradição gaúcha, da realidade do contexto, pois na cidade apresenta alguns grupos de invernadas, tanto de piquetes quanto do CTG.

Conforme salienta Gonçalves (2007, p.82):

Não há, portanto, uma cultura de movimento, mas culturas de movimentos que estão presentes nas experiências dos educandos. Acredita-se que as condições de possibilidade de re-significação dos valores, está justamente na mediação entre os conhecimentos culturais e os da escola, a que deve ser feita pelo professor num clima emancipatório. 
E assim trabalhando com os alunos movimentos ajustados ao ritmo da música os mesmos tiveram a oportunidade de através da musicalidade da linguagem da cultura deles, reconhecer o seu próprio corpo.

Trabalhou-se a música "O cravo brigou com a rosa" com a apresentação do teatro de fantoches a qual foi apresentado à dramatização e ao mesmo tempo se foi trabalhando a amizade, o coleguismo e o respeito ao próximo, procurando estimular o lúdico infantil. Esta aula, para surpresa, foi de grandes reflexões, pois, ao final da aula a professora percebe a imagem de um aluno em uma fotografia a qual havia sido fotografado no momento em que na dramatização, o cravo fala sobre respeitar os colegas, não falar palavrões. Conforme a professora foi neste exato momento que este determinado aluno faz uma expressão de quem esta refletindo sobre as suas atitudes em sala de aula.

No momento em que os alunos fizeram a dramatização com os fantoches estes destacaram através do diálogo, a boa convivência uns com os outros, enfatizando que respeitar, procurando ter uma convivência adequada com os colegas e demais pessoas, o que chamou muito a atenção das educadoras.

A aula proporcionou a interação entre a turma onde estes confeccionaram os seus fantoches brincaram de roda cantando a música em completa harmonia e felicidade. Conforme Tardif (2007, p.23).

\footnotetext{
Ora, a escolarização repousa basicamente sobre interações cotidianas entre os professores e os alunos. Sem essas interações a escola não é nada mais que uma imensa concha vazia. Mas essas interações não acontecem de qualquer forma: ao contrário, elas formam raízes e se estruturam no âmbito do processo de trabalho escolar e, principalmente, do trabalho dos professores sobre e com os alunos.
}

No final da semana trabalhou-se a música "A canoa virou", em que os alunos cantaram ao som da música e iam ao mesmo momento olhando para o cartaz, enquanto com uma régua a educadora apontava para as palavras escritas. Após confeccionaram um barco de dobradura, pintaram e colaram no cartaz. No desenvolvimento da aula foi procurado trabalhar a oralidade, motricidade, mas o auge foi quando professora fez para os alunos um barco enorme em dobradura com papel pardo e convidou os mesmos para que cada um cortasse o contorno de suas fotos, material que a professora já havia preparado anteriormente para o desenvolvimento da sua aula, estes cortaram, colaram um palito em sua foto e a colocaram no barco. A impressão que se tinha neste momento pela conversa e atitudes dos alunos é que estes se imaginavam, realmente navegando dentro do barco. E ao final da aula foram todos 
brincar no pátio de roda e cantar a musica "A canoa virou”. De acordo com Centurión (2004, p. 67).

Movimentos ajustados ao ritmo das canções: Brincadeira de roda. Além de desenvolver a oralidade, a brincadeira de roda possibilita o movimento ajustado ao ritmo da canção. Por exemplo, a música A canoa virou pode ser cantada pelos alunos em brincadeira de roda.

E assim o projeto foi se desenvolvendo com a música, o corpo, a brincadeira procurando sempre com que os alunos refletissem a cada melodia escutada ou seja a leitura sensorial exercitada apoiada no sentido na visualização das atividades propostas. Passando assim pelas mais variadas músicas entre estas, "Meu chapéu tem três pontas", "Escravo de Jô", "Cabeça, ombro, joelho e pé", "Fui morar numa casinha", sempre incentivando com que o aluno passe a apreciar a música, que este tenha o estimulo do raciocínio lógico, proporcionando com que desenvolva a corporeidade que explore movimentos ajustados ao ritmo da música e para que venham a reconhecer o seu próprio corpo.

Com a música: "Borboletinha tá na cozinha" a proposta foi fazer com que os alunos pudessem perceber através da música a escrita, interagir entre os colegas, desenvolver a criatividade, motricidade na confecção de móbile de borboletas. Prepararem uma salada de frutas com os alunos tendo como objetivo conscientizar sobre a importância de fazermos uma alimentação com qualidade. De criarmos hábitos saudáveis e de forma equilibrada que venham ajudar a manter o corpo em equilíbrio e perfeito.

Ao trabalhar com as músicas "Ciranda, Cirandinha" e "Nesta Rua" a proposta foi fazer com que os educandos interagissem através da música cantando e percebendo a escrita dos textos. Ao confeccionarem uma rua em TNT, através da conversa informal entre todos, a professora ia sugerindo que estes fossem reconhecendo as diferentes moradias.

Conforme os alunos faziam a rua ladrilhada com diferentes tonalidades de papel laminado, era explicado que na cidade há diferentes ruas, ruas mais largas outras mais estreitas, algumas de dupla mão outras eram de uma mão só. Que para se movimentar nas ruas existem regras e sinais no transito que devem ser obedecidas para minguem se machucar e que algumas dessas ruas eram asfaltadas outras de paralelepípedos como a rua da nossa escola e outras de pedra como a rua que passa na lateral da escola.

A aula foi de completa interação e aprendizagem, pois todos trocavam ideias uns explicando para o outro o que sabia sobre as diferentes ruas e diferentes situações que já haviam presenciado no transito por imprudência deles mesmos ou dos pais e conhecidos. 
E para encerrar o projeto convidou-se mais duas colegas que estavam terminando de desenvolver projetos de estudos diferentes na mesma escola, porém com outras turmas, para participar e proporcionar uma exposição dos trabalhos com os alunos, pais e comunidade escolar. Pois durante todo o tempo de aprimoramento de formação continuada, da apropriação das leituras teóricas construiu-se aprendizagens da importância e responsabilidade dos professores, de trazer a família, a comunidade escolar para dentro da escola, para participar do contexto escolar. E assim terminada a pratica com os funcionários, professores, todos envolvidos em ajudarem e organizar, a exposição, e com os pais dentro da escola olhando encantados os trabalhos dos seus filhos tentando ajudar de alguma forma em qualquer eventualidade, o mais importante, todos em completa interação em busca de um único objetivo "o melhor pela educação daqueles alunos e filhos".

\section{Conclusões}

O desenvolvimento do projeto educacional Estágio proporcionou à aquisição de novos conhecimentos que são de total importância para que se venha a ter um bom desenvolvimento enquanto educadora. A experiência ocasionou subsídio para por em prática tudo o que for necessário diante das dificuldades, que serão encontradas em sala de aula.

A partir das aprendizagens percebe-se que tem que haver um constante aperfeiçoamento por parte do educador, para que este tenha sucesso profissional. O professor deve estar sempre se atualizando, pois a educação está sempre evoluindo, este deve sempre estar refletindo sobre a teoria com a prática, obtendo subsídios para entender os problemas que as instituições escolares enfrentam e com isso poder superá-los.

Na prática educacional houve a possibilidade de perceber, que esta foi uma ocasião de suma importância para professoras pedagogas, pois neste momento que tem-se a oportunidade de ver a realidade do contexto escolar, saímos da universidade, onde é proporcionado um leque de estudos das disciplinas teóricas, e enfrenta-se a realidade concreta vivenciada na sala de aula, com isso reconstruindo situações de aprendizagens que somente a pratica em sala de aula permite, como por exemplo, ter a percepção do que é ser docente na Educação Infantil.

\section{Referências}

BRASIL. Referencial curricular nacional para a educação infantil /Ministério da Educação e do Desporto, Secretaria de Educação Fundamental. — Brasília: MEC/SEF, 1998.3v.: il. 
CENTURIÓN, Marília. Jogos, projetos e oficinas para educação infantil. Marília

Centurión...[ET AL.]. - São Paulo: FTD,2004.

Gonçalves, S. REFLEXÕES ACERCA DO PAPEL DA RE-SIGNIFICAÇÃO DO CORPO PELA EDUCAÇÃO FÍSICA ESCOLAR, FACE AO ESTEREÓTIPO DE CORPO IDEAL CONSTRUÍDO NA CONTEMPORANEIDADE Revista Conexões v. 5, n. 1, 2007.

HERNANDEZ, Fernando. A Organização do Currículo por projetos de trabalho. 5 ed. Porto Alegre: Artmed, 1998.

TARDIF, Maurice; LESSARD, Claude. O trabalho docente. Elementos para uma teoria da docência domo profissão de interações humanas. Petrópolis/RJ: Vozes, 2007. 